\title{
COMBINING THERMAL IMAGING WITH PHOTOGRAMMETRY OF AN ACTIVE VOLCANO USING UAV: AN EXAMPLE FROM STROMBOLI, ITALY
}

\author{
ZOË E. WAKEFORD* (zoewakeford@abdn.ac.uk) \\ MAGDA CHMIELEWSKA (magda.chmielewska@abdn.ac.uk) \\ JOHN A. HowELL (john.howell@abdn.ac.uk) \\ University of Aberdeen, Aberdeen, UK \\ DOUGAL A. JERRAM ${ }^{\mathrm{a}, \mathrm{b}}$ (dougal@ dougalearth.com) \\ ${ }^{a}$ Centre for Earth Evolution and Dynamics (CEED), University of Oslo, Oslo, Norway \\ ${ }^{b}$ DougalEARTH Ltd., Solihull, UK \\ MALCOLM J. HoLE (m.j.hole@abdn.ac.uk) \\ University of Aberdeen, Aberdeen, $U K$
}

\begin{abstract}
Volcanoes are a potential hazard to over 750 million people worldwide. Accessing them to install monitoring equipment can be logistically challenging and dangerous.

Traditional monitoring equipment is expensive and not available to many communities living within the hazardous region. We propose a potential new, low-cost method to address these challenges using a unique $3 D$ thermal photogrammetric modelling workflow. The data acquisition and procession part of this workflow has been tested on Stromboli, a volcano in the Aeolian Islands of Italy and an excellent natural laboratory for volcano monitoring. Unmanned aerial vehicles were deployed at the volcano to acquire both visual and thermal infrared imagery. Both datasets were then digitally processed to produce respective $3 D$ virtual outcrop models. Finally, the two datasets and models were integrated to produce the first $3 D$ thermal photogrammetric model of an active volcano. The result is an easy-to-use workflow applicable to any volcano in the world. This low-cost monitoring system could be deployed in developing countries and remote areas otherwise hindered by limited budgets and access.
\end{abstract}

KEYWORDS: photogrammetry, unmanned aerial vehicle, volcanic hazard, thermal,

Stromboli, 3D modelling

\section{INTRODUCTION}

Across the globe, over 750 million people live in close proximity to active volcanoes 
WAKEFORD et al. Combining thermal imaging with photogrammetry of an active volcano using UAV: an example from Stromboli, Italy

$(\leq 100 \mathrm{~km}$; Cottrell, 2015) which pose a significant risk of displacement and loss of life. Predicting such impending dangers is critical to alerting local communities, allowing time for evacuation and saving lives, thus reducing the chances of a volcanic disaster. Unfortunately, this ideal scenario is hindered by the costs of traditional sensor equipment, ground inaccessibility and danger to scientists to monitor and study the culprit volcanoes. Thus, a low-cost remote sensing measurement technique such as photogrammetry or thermal infrared imagery has a profound advantage under such circumstances (e.g. Blackett, 2017; Harvey et al., 2016).

In the last decade, unmanned aerial vehicles (UAVs) have been applied to mapping a variety of geological features (McGonigle et al., 2008; Pisciotta et al., 2016; Wilkinson, 2017). They have had a wide range of applications including to the spatial mapping of volcanoes (Blackett, 2017; Jordan, 2015; Sheng et al., 2010). A significant advantage of using UAVs is that they allow high resolution data to be collected from a relatively safe distance from the geohazard (Blackett, 2017; Tarigan et al., 2017; Wilkinson, 2017). They can be utilised in any geoscience survey where access is otherwise difficult or hazardous (Wilkinson, 2017), such as vertical cliff sections or unstable volcanoes (Jordan, 2015). The application of UAVs becomes increasingly useful with the addition of imaging payloads (weighing up to $10 \mathrm{~kg}$; Lombardo, 2016), such as lidar scanners and high-quality digital cameras (Wilkinson, 2017), as they reduce the costs and risks of operating helicopter and aircraft surveys (Harvey et al., 2016; McGonigle et al., 2008; Romeo et al., 2016), produce spatial resolution comparable to ground-based remote sensing (Blackett, 2017), increase the temporal resolution compared to traditional air-borne surveys (McGonigle et al., 2008) and ease the logistics of photogrammetric surveys (Donato Melita et al., 2015). With falling costs of UAVs, sensor miniaturisation and the advance of battery technology, further opportunities have been revealed for photogrammetric studies from UAVs, where the collected datasets are at such high quality that better mapping of landscape characteristics can be produced compared to lower-resolution data obtained by conventional manned aircraft $(\sim 10-100 \mathrm{~cm})$ and satellites $(>50 \mathrm{~cm})$ (Harwin and Lucieer, 2012). UAV photogrammetry can also be combined and compared with ground-based photogrammetry to study and monitor efficiently the evolution of volcanically active zones and highlight anomalies and details typically lost in ground-based campaigns alone (Pisciotta et al., 2016; Romeo et al., 2016).

Thermography is a branch of remote sensing that measures the infrared radiation emitted from any object or mass due to their internal thermal conditions. Based on the physical principle that any object or mass hotter than absolute zero emits infrared radiation from within the electromagnetic spectrum, the technique of thermal remote sensing converts the infrared energy into radiation temperature signatures, termed "apparent temperature" (Spampinato et al., 2011). Thermal cameras and radiometers are passive sensors that are able to record this apparent temperature (Chio and Lin, 2017) and can provide information on the target emitter, e.g. type, health or material of the target (Gade and Moeslund, 2014; Sheng et al., 2010). Measurements of the infrared region of the spectrum, and thus the apparent temperature, are extremely useful when applied to monitoring volcanic activity (Blackett, 2017), as the activity involves the transfer of thermal energy from within the Earth to the surface observed as lava flows, lava lakes or degassing vents (Blackett, 2017). Thermal infrared remote sensing has improved significantly in the past 50 years (Blackett, 2017), and is now recognised as a powerful and advantageous method for collecting, analysing and modelling temperature variations 
(Calvari et al., 2005; Sheng et al., 2010). Since its first application on two Alaskan volcanoes, Pavlof and Shishaldin, in 1997 and 1999 (McGimsey et al., 1999), thermal remote sensing has been proven useful in studying: (1) Strombolian-type explosions and degassing (e.g. Ripepe et al., 2004); (2) the distribution of vents and volcanic features (e.g. Harris and Stevenson, 1997); (3) the magma depth and migration within central conduits and feeder dykes (e.g. Harris et al., 2003; Sheng et al., 2010); (4) fracture propagation prior to an eruption (e.g. Bonaccorso et al., 2003); (5) thermal and effusion flux from active lava flows (e.g. Ganci et al., 2011); and (6) the volcano's activity status (e.g. Blackett, 2017).

Thermal videos have been used to track the evolution of an eruption, providing information on dynamics such as event chronology and frequency, activity style and repose times (e.g. Harris et al., 2003). Prior to the utilisation of UAVs, thermal infrared monitoring in volcanology was traditionally conducted using satellite-borne, aircraft-borne and ground-based remote sensing instruments (Harris et al., 2003; James and Robson, 2012), but the introduction of the UAV has revealed new and efficient opportunities to monitor volcanic activity (e.g. Chio and Lin, 2017; Harris et al., 2003). Previously, UAVs had been used to collect data on the gas flux from a volcanic eruption plume (McGonigle et al., 2008), and, more recently, UAVs have been carrying forward looking infrared radiometers (FLIR; Nishar et al., 2016). Thus, remote sensing from an unmanned drone allows the rapid and safe collection of thermal infrared data in areas otherwise inaccessible and/or dangerous (Harvey et al., 2016).

Virtual outcrop (VO) models help to visually examine a target area and analyse its spatial form in relation to its elevation (Tarigan et al., 2017) and to reveal topographical, geological and geotechnical information without the need to set foot on the target (Wilkinson, 2017). Such 3D models can be produced using either visual red, green, blue (RGB) or thermal infrared (TIR) imagery (e.g. Hoegner et al., 2016), using the same photogrammetric modelling process for both image types. Traditionally in stereo photogrammetry, the 3D location and pose of the camera(s) must be known (Westoby et al., 2012) in order to correctly geo-reference the collected images, and the requirement of ground control points (GCPs) was a severe hinderance for close-range studies in the past (e.g. Harwin and Lucieer, 2012; Westoby et al., 2012). However, the introduction of the structure-from-motion (SfM) photogrammetric method automatically computes camera poses, together with reconstructing environments using an iterative bundle adjustment technique that matches common features within the overlapping images (Harwin and Lucieer, 2012; Maset et al., 2017; Tarigan et al., 2017; Westoby et al., 2012). Software solutions such as Agisoft PhotoScan, Pix4D, Autodesk ReCap, Reality Capture, and PhotoModeler are able to perform the bundle adjustment to solve the camera position(s) and orientation (Harwin and Lucieer, 2012). Multiple photographs are combined creating thousands to millions of data points, commonly referred to as "sparse point clouds" (Harwin and Lucieer, 2012; Tarigan et al., 2017; Wilkinson, 2017). For high-resolution terrain surface reconstruction, denser point clouds are required. Using the multi-view stereopsis (MVS) technique and bundle adjustment (Furukawa and Ponce, 2010), the sparse point cloud is expanded and filtered to make the point cloud more dense.

3D models or VOs first appeared as a tool for field geologists in the early 2000s (Pringle et al., 2006). Early examples were generated using terrestrial laser scanners and early work focussed on analysing the point clouds generated by the scanner (Bellian et al., 2005). Subsequent developments focussed on the generation of triangulated surface models textured with high-resolution digital images (e.g. Buckley et al., 2008). These were widely 
WAKEFORD et al. Combining thermal imaging with photogrammetry of an active volcano using UAV: an example from Stromboli, Italy

used for a variety of geological applications (e.g. Buckley et al., 2010; Enge et al., 2007; James and Robson, 2014; Nieminski and Graham, 2017; Tonkin and Midgley, 2016). Specialist software such as LIME (Buckley et al., 2019) and VRGS (Hodgetts, 2013) were developed for the visualisation and interpretation of the data. In the early 2010s, the development of cheap, reliable UAVs (Harwin and Lucieer, 2012), coupled with developments in photogrammetry, especially the emergence of SfM (Fonstad et al., 2013; Westoby et al., 2012), led to a wider-spread adoption of the virtual outcrop approach as VOs became accessible to a wider range of scientists (Howell et al., 2014). VOs are typically overlain with RGB images, however, Kurz et al. (2008) and Buckley et al. (2013) overlaid terrestrial hyperspectral imagery on the lidar-derived virtual outcrops and Hoegner et al. (2016) fused thermal images to an RGB-based point cloud.

The application of UAVs in RGB and TIR image collection is fast becoming commonplace within both volcanological and environmental circles (Westoby et al., 2012). Their nadir and oblique points of view reduce geometrical distortion in the collected images in comparison to those taken by ground-based cameras (Lombardo, 2016), and the generated 3D point clouds can be accurate to $2.5 \mathrm{~cm}-4 \mathrm{~cm}$ when the images are taken at $\sim 50 \mathrm{~m}$ distance from the target with evenly distributed GCPs and high degree of overlap (Harwin and Lucieer, 2012). Integration of these two types of image datasets has been studied, in particular, in building inspection disciplines (e.g. Maset et al., 2017) and in archaeological heritage documentation (e.g. Brumana et al., 2013). However, to the best of our knowledge, no UAV-based RGB + TIR 3D photogrammetric technique has been applied to active volcanoes. The objective of this study is to, therefore, present a workflow on building a 3D thermal model of an active volcano from both visual (RGB) and thermal (TIR) images collected using unmanned aerial vehicles. This workflow is the first stage in a project aimed at developing a low-cost, autonomous system for monitoring volcanoes anywhere in the world.

\section{STUDY AREA}

To test the possibility of building a 3D thermal model, we chose Stromboli, a volcanic island off the coast of Sicily, for the case study. Known as the "Lighthouse of the Mediterranean", Stromboli forms a 2.6-km-high composite cone (Patanè et al., 2017; Tibaldi, 2003) rising from the floor of the Tyrrhenian Sea, at the northern tip of the Aeolian Islands, southern Italy (Fig. 1). The island itself only represents the emerged $924 \mathrm{~m}$ above sea level (a.s.l.) of the volcano $-12.2 \mathrm{~km}^{2}$ in area (Jerram et al., 2017; Lopes, 2005). The island of Stromboli has been shaped over the last 100,000 years by separate extrusive growth and flank collapse events. After a series of flank collapses during the Holocene, a 2-km-wide depression scar (the Sciara Del Fuoco; Figs. 1 and 2) developed on the northwest flank of the volcano (Tibaldi, 2001). The current volcanic activity originates from vents within a $250-\mathrm{m}$-long by $150-\mathrm{m}$-wide crater terrace at the summit of the Sciara Del Fuoco (C1, C2 and C3 in Fig. 1; Bonaccorso et al., 2003; Jerram et al., 2017). Lying at $750 \mathrm{~m}$ a.s.l., these craters are overshadowed by a natural balcony between the Vancori crest at $924 \mathrm{~m}$ and the Pizzo Sopra la Fossa crest at $918 \mathrm{~m}$ (Fig. 1; Jerram et al., 2017). This natural balcony provides an excellent view for tourists to witness Stromboli's volcanic activity. Such activity is characterised by persistent low-energy Strombolian-type explosions, erupting lava bombs, black scoria and ash, every $10-20$ minutes (Aiuppa et al., 2010; Calvari et al., 2005). The persistent Strombolian explosions are considered to be 


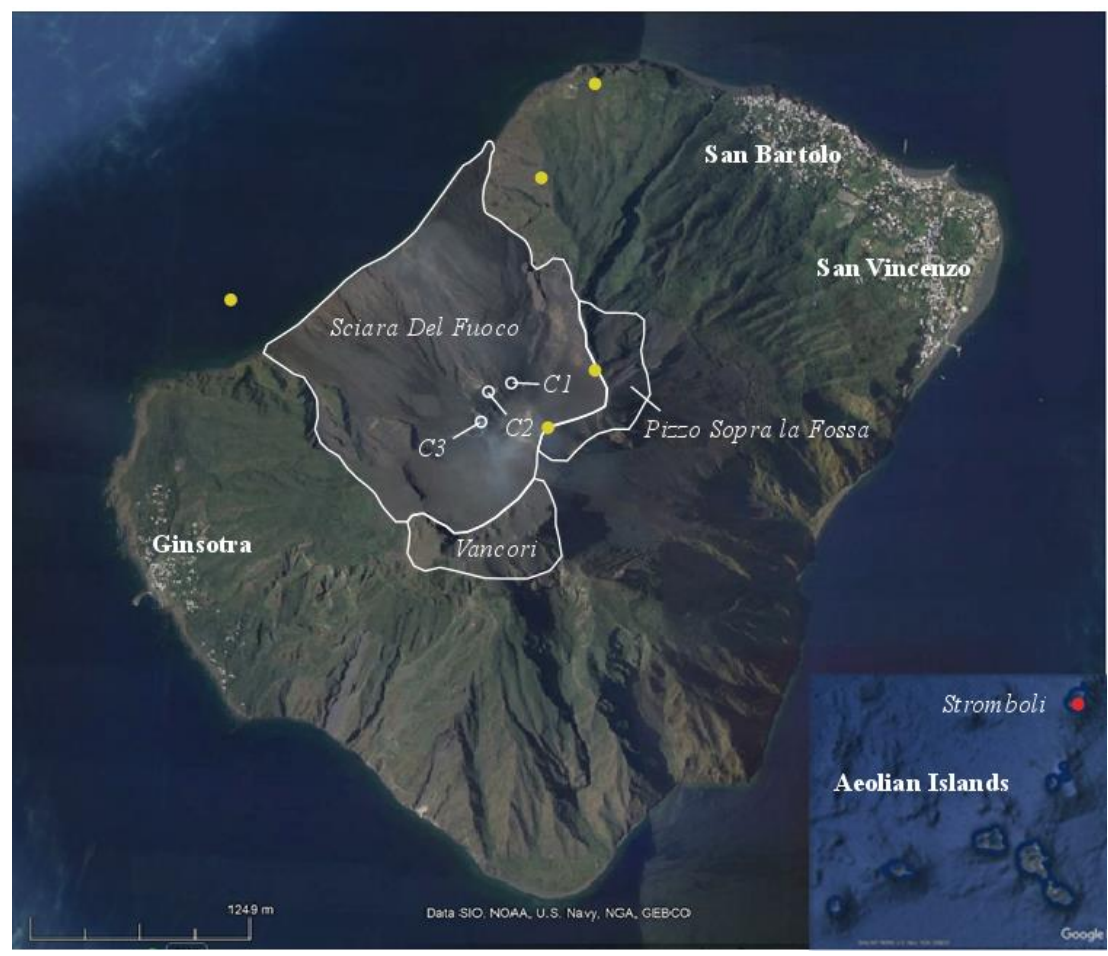

FIG 1. Google Earth image of Stromboli island, Aeolian Islands, Italy. C1, C2 and C3 depict the locations of the three continuously active craters. The landslide scar, Sciara Del Fuoco, and the two edifice crests, Vancori and Pizzo Sopra La Fossa, are outlined. The three settlements (Ginostra, San Bartolo and San Vincenzo) are labelled. Yellow dots pinpoint UAV launch sites for this study. Inset illustrating Stromboli's location within the Aeolian Islands.

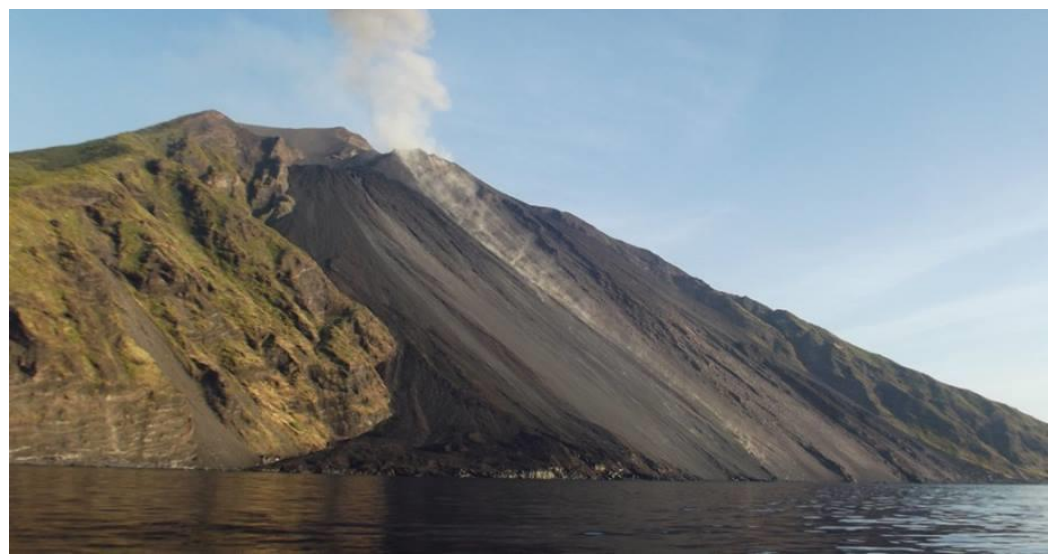

FIG 2. Photograph of the landslide scar, Sciara Del Fuoco, where lava flows are usually channelled towards the sea. After the 2002 - 2003 eruption, a tsunami buoy was deployed at the base of the Sciara to detect any significant levels of water displacement produced by falling debris. Photograph taken from the northwest coast of the island (Fig. 1), facing south. 
WAKEFORD et al. Combining thermal imaging with photogrammetry of an active volcano using UAV: an example from Stromboli, Italy

caused by a delicate equilibrium between a shallow, gas-poor, strongly-porphyritic basaltic magma reservoir and a deeper, gas-rich, weakly-porphyritic magma refilling into the shallow reservoir (Pioli et al., 2014). The dynamics of the system being characterised by the near consistent volcanic activity, and a record of multiple episodes of magma recycling, as recorded in the crystal populations from the resulting erupted porphyritic magmas (e.g. Morgan et al., 2007). Larger-energy eruptions (paroxysms) are generated due to destabilisation of the reservoir by the injection of the weakly-porphyritic magma (Pioli et al., 2014). Occasionally, lava flows are effused from the craters (Lodato et al., 2007), and are usually channelled towards the sea along the Sciara Del Fuoco landslide scar (Fig. 2) without presenting a hazard to the neighbouring villages of San Bartolo, San Vincenzo and Ginostra (Fig. 1; Madonia and Fiordilino, 2013). However, the Sciara Del Fuoco has remained unstable for 13,000 years, resulting in approximately 8 recorded major collapse events (Tibaldi, 2001), the last few occurring in 1975 (Capaldi et al., 1978) and 1985 (De Fino et al., 1988). On 30 December 2002, a collapse event generated a small tsunami (Bonaccorso et al., 2003), significantly endangering inhabitants. Occasional paroxysms can also cause damage to property and loss of lives (Madonia and Fiordilino, 2013). Violent eruptions of ash and lava bombs rained down on the villages in 1912, 1919 and 1930, killing a total of 12 people and injuring over 22 others (Lopes, 2005). The latest paroxysm occurred very recently on 3 July 2019. At 16:46 (local time), a large ash cloud erupted from the summit craters, raining hot ash down on to the local villages, and effusing lava flows towards Ginostra. 1 person was killed by this event, with another 70 evacuated from the island (BBC News, 2019). Prior to the eruption, the INGV-CT STR1_EHZ_IT seismometer stationed on the volcano recorded a large spike in volcanic tremors at approximately 15:01 (local time) (INGV, 2019). At the time of writing, the activity at Stromboli was still in a heightened phase, and access to the volcano restricted. So, while Stromboli's eruptive activity is usually predictable and well constrained, attracting thousands of tourists a year, major eruptions and paroxysms can cause significant damage and pose a threat to its inhabitants and visitors. Thus, numerous and continuous monitoring efforts have been made since 1991 to prevent and/or mitigate volcanic disasters, with monitoring techniques continuously evolving even today. One such new approach (Fig. 3) is presented in this article.

\section{WORKFLOW AND RESULTS}

Initial reconnaissance was undertaken in September 2015 and the main fieldwork was conducted in May 2017 on Stromboli volcano to carry out the photogrammetric survey. Under good weather conditions (sunny day with clear skies and calm winds), two different drones were deployed from several different locations (yellow dots in Fig. 1). A DJI Phantom 4 Standard UAV, equipped with a 12-megapixel CMOS 1/2.3" sensor type, was used to collect the visual RGB photographs. To increase flight safety and minimise the likelihood of the drone being hit by incandescent ejecta, manual piloting of the Phantom 4 was adopted, flying at an altitude of $\sim 120 \mathrm{~m}$ above the target Sciara Del Fuoco. This produced images with a spatial resolution (expressed as ground sampling distance (GSD)) of $\sim 7.8 \mathrm{~cm}$. A total of 423 geo-tagged RGB images were collected with an average of $60 \%$ image overlap. The TIR imagery was collected using the DJI Inspire 1 UAV equipped with a Zenmuse XT Advanced Radiometry sensor with a 640-X-512-pixel resolution, $9 \mathrm{~mm}$ lens and a $30 \mathrm{~Hz}$ frame rate. During the 13-minute flight, 226 geo-tagged TIR photographs were 


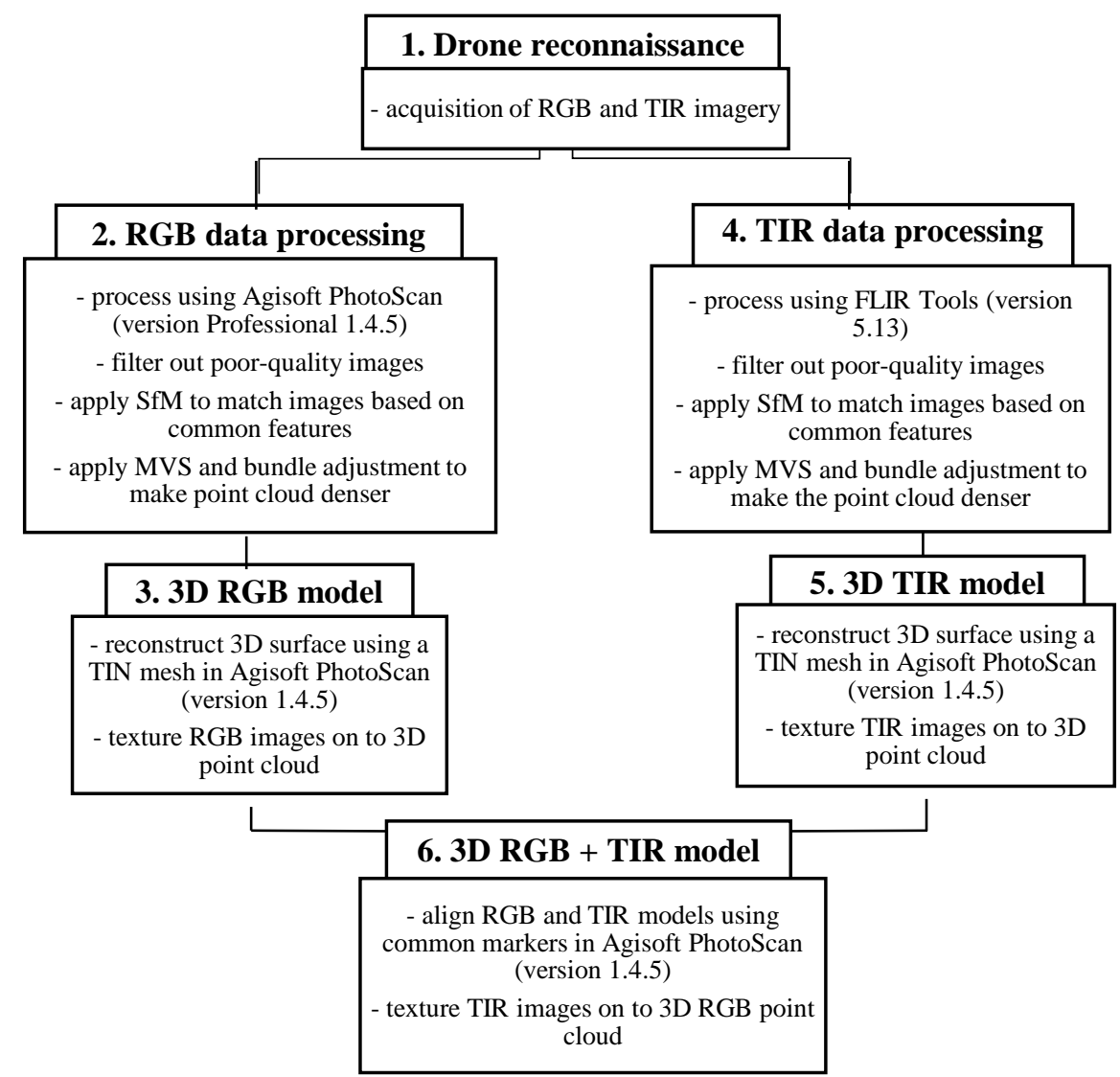

FIG. 3. Flowchart illustrating workflow adopted to create a 3D thermal photogrammetric model. RGB = red, green, blue visual images. TIR = thermal infrared images. $\mathrm{SfM}=$ structure-from-motion photogrammetry method. MVS = multi-view stereopsis photogrammetry method. TIN = triangulated irregular network mesh.

acquired (average of $80 \%$ image overlap) from an altitude of $~ 120 \mathrm{~m}$ above the Sciara Del Fuoco, producing images with a GSD of $\sim 38 \mathrm{~cm}$. Prior to the thermal flight, the ambient temperature was set to $22{ }^{\circ} \mathrm{C}$ and the emissivity for the basaltic lava was set to 0.96 to calibrate the thermal recordings. The thermal imagery was stored as radiometric JPEG (R-JPEG) data in the grey colour palette, which store the temperature data in each pixel and can be analysed easily using the FLIR Tools software (version 5.13; FLIR Systems Inc., 2019).

The photogrammetric image-processing stage started with the removal of poor-quality RGB images; i.e. blurry images due to flight motion or those out of focus, images captured outside of the study area, or duplicate images. The remaining 326 RGB images were then processed using the SfM and MVS techniques following standard methodologies (e.g. Furukawa and Ponce, 2010; Westoby et al., 2012). The image processing was conducted using the popular commercial software Agisoft PhotoScan (version Professional 1.4.5). PhotoScan was able to detect common features within each image and matched the correspondences across the dataset. Next, a bundle adjustment algorithm was applied to 
WAKEFORD et al. Combining thermal imaging with photogrammetry of an active volcano using UAV: an example from Stromboli, Italy

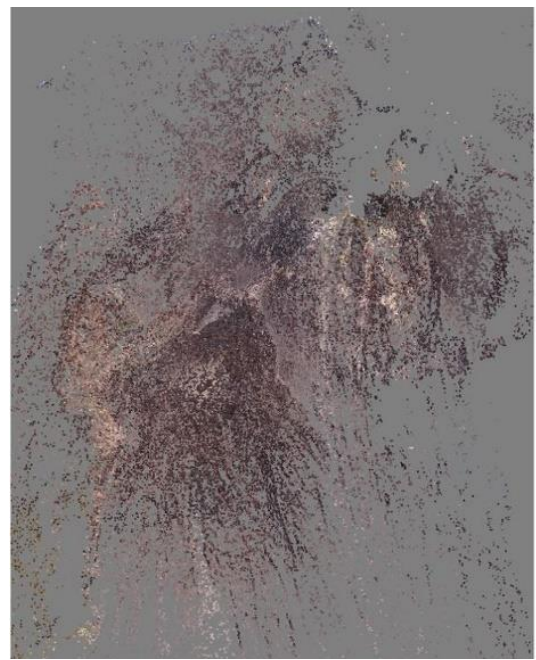

(a)

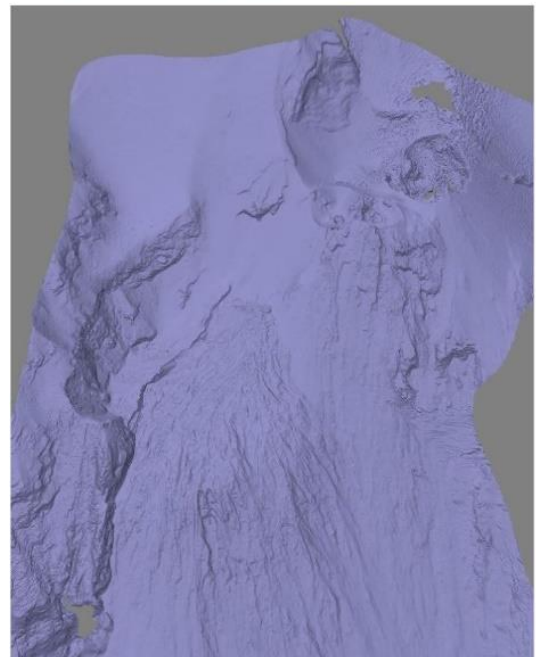

(c)

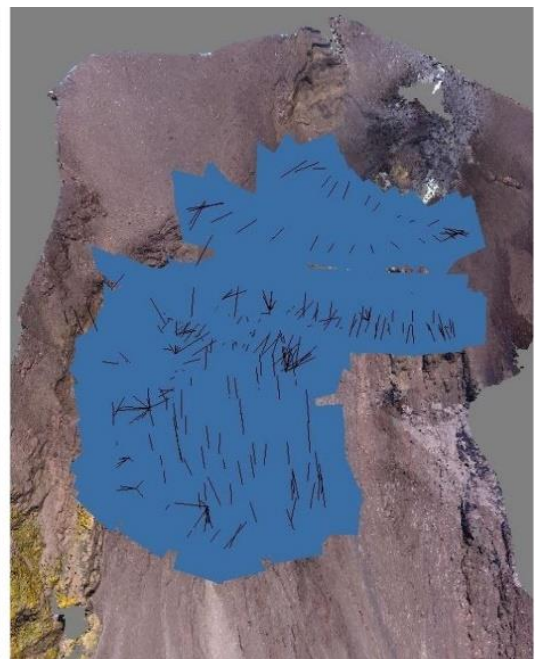

(b)

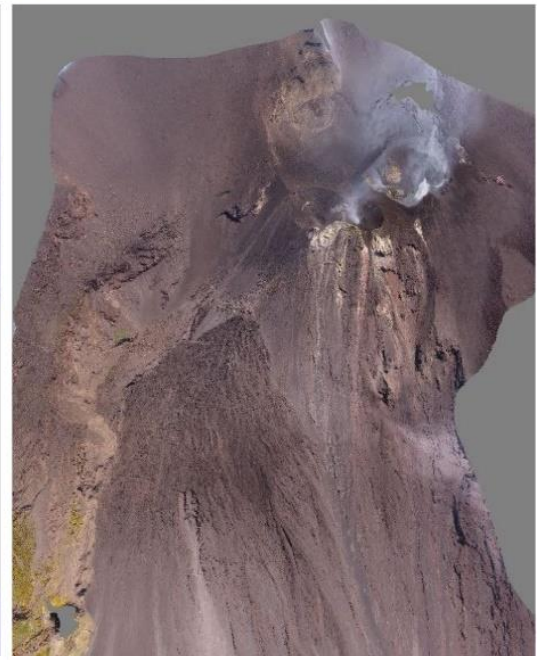

(d)

FIG 4. Data processing steps in Agisoft PhotoScan (version Professional 1.4.5) for 3D reconstruction of Stromboli's crater zone and the Sciara Del Fuoco (steps 2 and 3 of Fig. 3): (a) sparse point cloud created by photo alignment of common features; (b) dense point cloud created by multi-view stereo image matching algorithms from original sparse point cloud (shaded in blue); (c) surface triangulated irregular network mesh reconstructed from 3D dense point cloud (shaded in purple); (d) textured 3D model created by wrapping source photos around the $3 \mathrm{D}$ mesh.

solve the camera orientations to produce a sparse 3D point cloud (Fig. 4a). MVS algorithms were than applied to make the point cloud denser (Fig. 4b). Finally, the denser 3D point cloud was used to reconstruct the 3D surface of the Sciara Del Fuoco, represented by a triangulated irregular network (TIN) mesh (Fig. 4c). The RGB images were textured on to the 3D model, adding detailed colour information to the 3D model (Fig. 4d).

As with the RGB images, the FLIR Tools software (version 5.13) was used to filter 

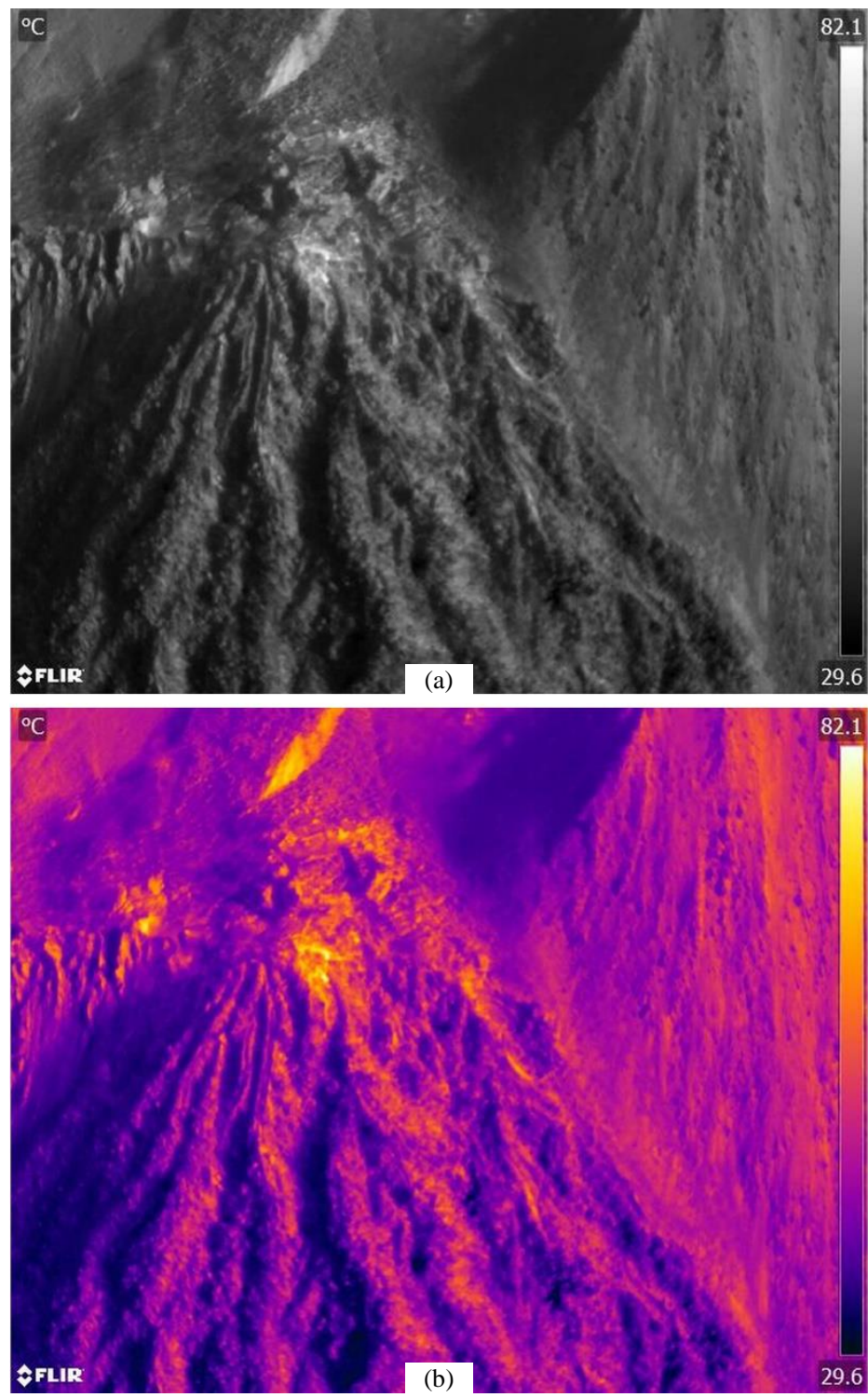

FIG 5. Comparison of the colour palettes used to illustrate thermal infrared data: (a) grey-scale colour palette; (b) iron colour palette. Images depicting the top of the Sciara Del Fuoco, facing southwest. Width of yellow signature feature at very top of (b) is $4 \mathrm{~m}$.

out poor-quality TIR images. The remaining 63 images were converted to the iron colour palette which offers a larger degree of contrast between similar temperatures (Fig. 5). The creation of the thermal 3D model followed the same photogrammetric processing flowchart as for the visual RGB 3D model (steps 2 and 3 in Fig. 3). Information regarding the positions and altitudes of the acquired TIR images were used for direct georeferencing. Even without the ancillary RGB information, PhotoScan was able to correctly align the TIR 
WAKEFORD et al. Combining thermal imaging with photogrammetry of an active volcano using UAV: an example from Stromboli, Italy

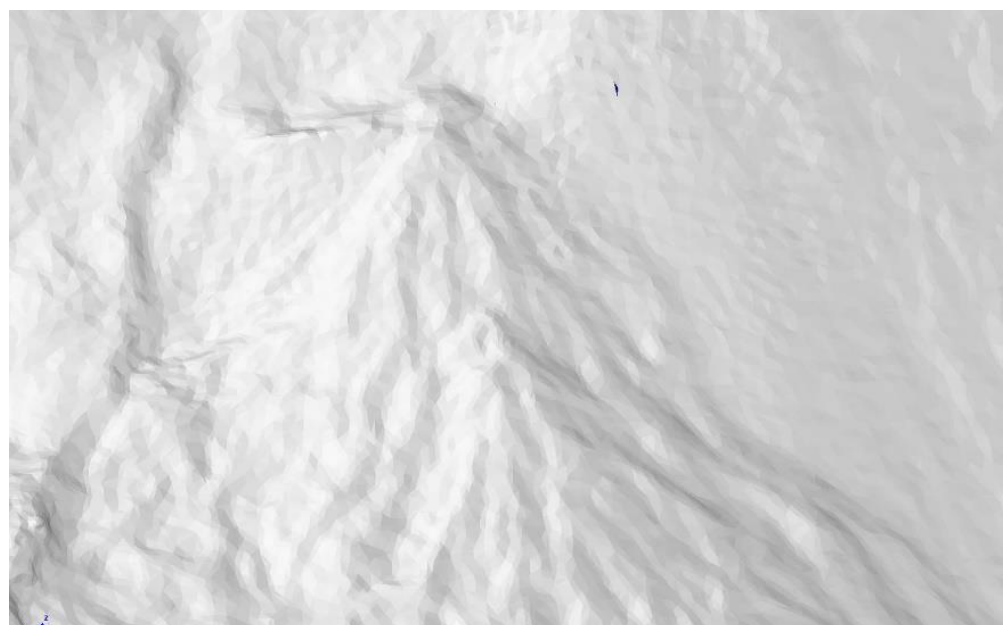

(a)

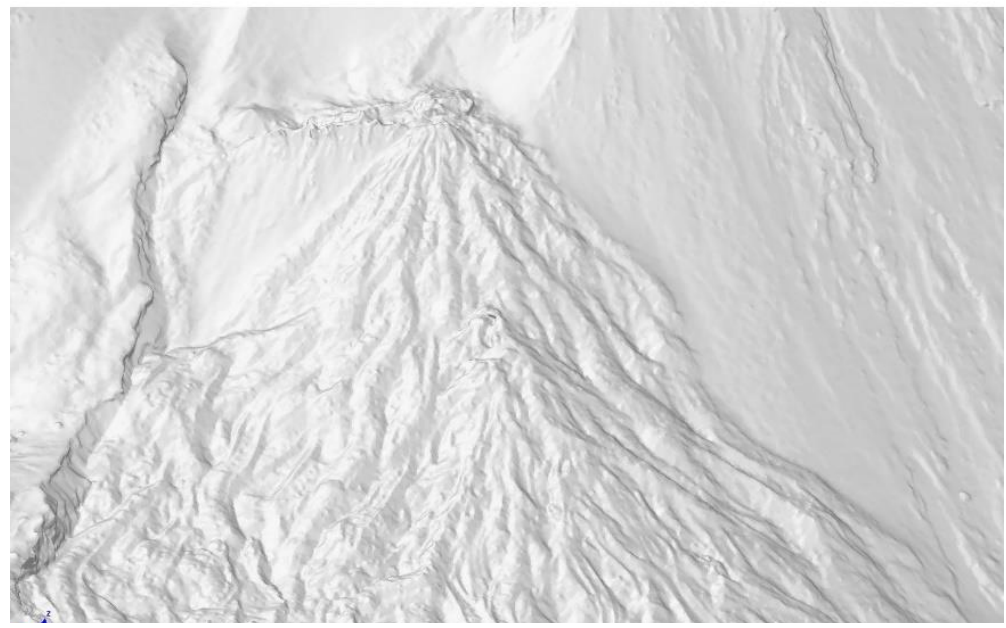

(b)

FIG 6. Digital surface reconstructed from (a) thermal infrared images and (b) visual RGB images. The TIR images in (a) constructed a lower-resolution 3D surface compared to the visual images in (b), whose structures are more defined. Images depicting the top of the Sciara Del Fuoco, facing southwest. Length of ridge running along the left side of the Sciara is $190 \mathrm{~m}$.

images to create a georeferenced thermal 3D model (Fig. 4d).

Given that the TIR imagery is of lower resolution and has a lower image quality (in terms of contrast and noise) compared to RGB imagery (e.g. Maset et al., 2017; Sledz et al., 2018), the detail of the reconstructed surface was less defined (Fig. 6) Therefore, it was desirable to merge the two. Both models were georeferenced from the GPS data captured by the UAVs during image acquisition. However, those data were not sufficiently accurate to produce models that could be directly aligned, and when they were compared there was a mismatch of several metres, especially in the z-direction (Skarlatos et al., 2013). 


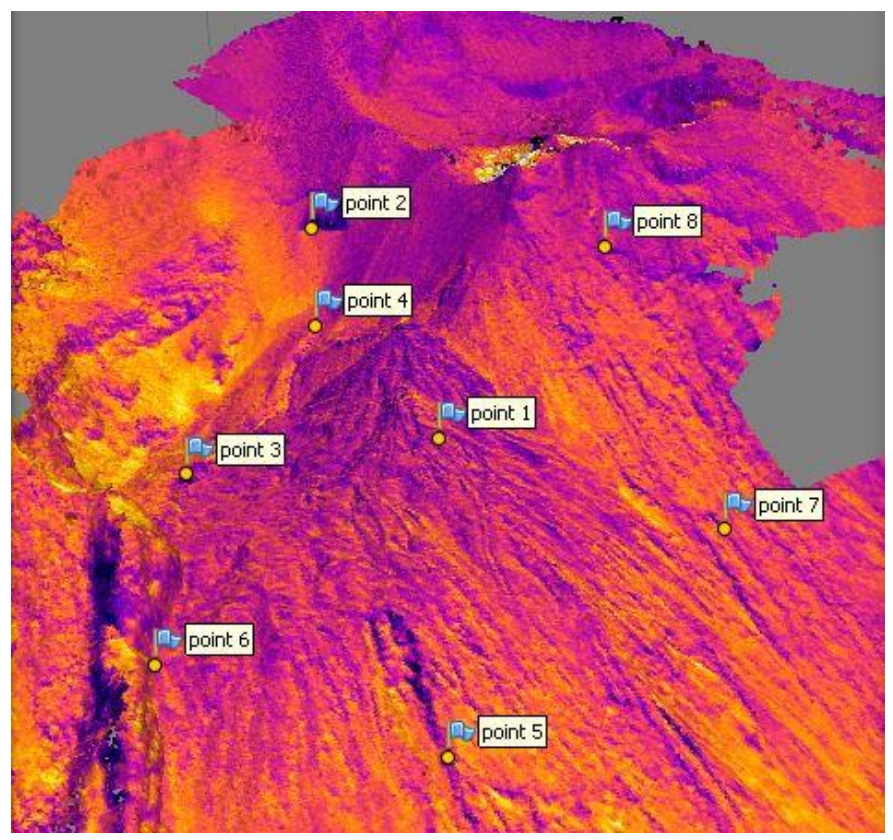

(a)

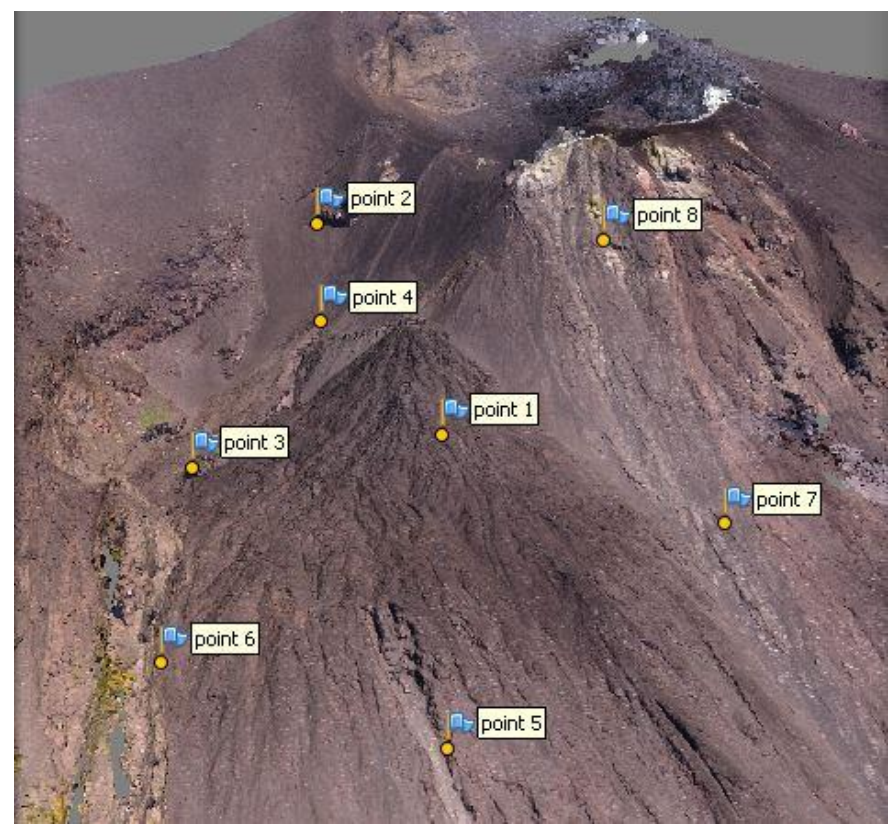

(b)

FIG 7. Markers (shown as flags) for both (a) thermal infrared and (b) visual RGB datasets, evenly distributed across the Sciara Del Fuoco study area. These markers were used for the RGB-TIR alignment in step 6 of Fig. 3. Images depicting the top of the Sciara Del Fuoco and the crater terrace, facing southwest. Distance between points 5 and 6 is $165 \mathrm{~m}$. 
WAKEFORD et al. Combining thermal imaging with photogrammetry of an active volcano using UAV: an example from Stromboli, Italy

Furthermore, it was desirable to overlay the thermal images on to the higher-resolution terrain model acquired from the RGB images. To achieve this merging, 8 correspondence points (markers) were selected in both datasets. These were points within the area that could clearly be picked in both models and were evenly distributed across the models (Fig. 7) for the RGB-TIR alignment. Using the implemented Agisoft PhotoScan (version 1.4.5) marker-based chunk alignment tool, the RGB models was selected as the reference model. This then allowed the orientation parameters of the TIR imagery to be automatically transformed into the same reference system as the RGB imagery. Once that was successful, both datasets were in the reference system mesh, generated from the RGB point cloud, which includes the clean and defined structures of lava flows on the Sciara Del Fuoco. The 3D surface and TIR imagery were then blended to create the final thermal texture map (Fig. $8)$.

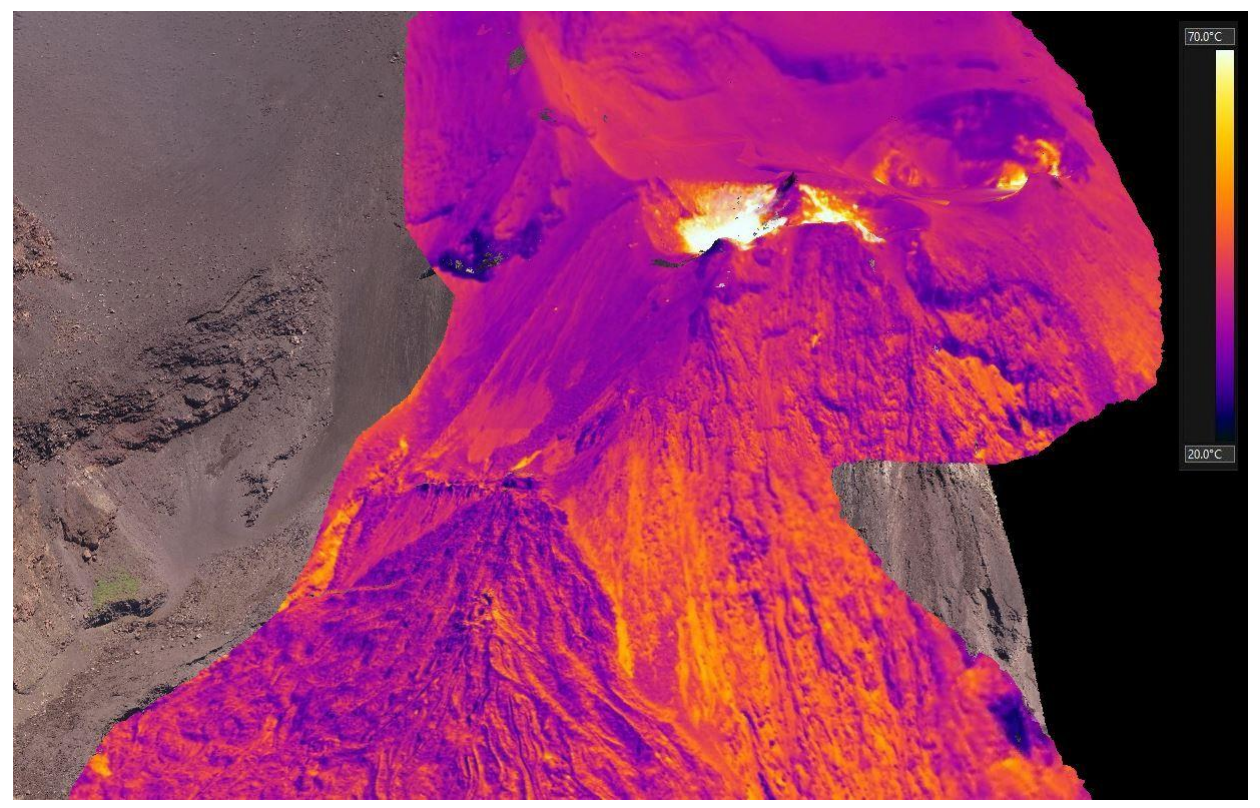

FIG 8. Final 3D thermal photogrammetric model of the active craters and the Sciara Del Fuoco at Stromboli volcano based on a combination of the RGB point cloud and the thermal infrared texture map. Using the iron colour palette, blue to purple colours represent low temperatures, while yellow to white colours represent warmer temperatures. Image depicting the top of the Sciara Del Fuoco and the crater terrace, facing southwest. Width of crater in west-east direction is $141 \mathrm{~m}$.

\section{DISCUSSION}

While this study presents the first 3D thermal model of Stromboli volcano, the approach of co-registering RGB and TIR imagery was already explored by Hoegner et al. (2016). They discuss five similar methodologies on the workflow of co-registering RGB and TIR image datasets, acquired with a remotely piloted aircraft system (RPAS), by using: 
(1) 2D line segments for every TIR image and corresponding RGB images; (2) both dense 3D point clouds from RGB and TIR images by 2D image projections of both point clouds; (3) $2 \mathrm{D}$ line segments in every TIR image and 3D line segments extracted from the dense 3D point cloud; (4) both dense 3D point clouds from RGB and TIR images using an iterative closest point (ICP) technique; and (5) both image datasets based on point features. Our workflow presented in this paper (Fig. 3) is similar to the fifth methodology of Hoegner et al. (2016), in that both RGB and TIR 3D point clouds are combined based on common markers to create a single 3D thermal model. However, Hoegner et al. (2016) applied their methodologies to a static, man-made building, whereas this workflow was applied to a dynamic, natural volcanic edifice. Thus, a novel technique to model volcanic activity in both RGB and TIR imagery acquired by UAVs is created, satisfying the aim of this paper.

Traditionally, photogrammetric modelling for volcano monitoring was based on imagery captured by satellite-borne, aircraft-based or ground-based remote sensing instruments. Satellite sensors, such as the moderate resolution imaging spectroradiometer (MODIS) and the advanced very-high-resolution radiometer (AVHRR), provide a longterm synoptic view of a volcano's life cycle, but produce low temporal resolution data of short-term thermal anomalies (Blackett, 2017). Manned aircraft surveys produce higher temporal resolution data than satellites but are expensive to deploy and cannot approach some geohazards, such as volcanic plumes, for risk to the operators during the flight (Donato Melita et al., 2015). Ground-based instruments are more advantageous in volcano monitoring as they acquire both high temporal and high spatial resolution data (Oppenheimer and Yirgu, 2002). However, fixed stations are liable to expensive breakdowns and the conduction of handheld image acquisition is dependent on ease of access to the target volcano for operators. UAVs offer a low-cost alternative that don't risk the safety of the operators and can be easily stored at nearby volcano observatories ready for quick and easy deployment. They can produce both high spatial and high temporal resolution imagery and can operate autonomously using their on-board GPS-driven autopilot (Remondino et al., 2011). As thermal infrared sensors can "see" through curtains of smoke and gas (Fig. 9), they can detect thermal anomalies and hotspots, allow the measurements and mapping of lava flows, and detect thermal anomalies and landslide scars which cannot otherwise be seen by the naked eye.

\section{Potential Applications of the Workflow}

Traditional methods for monitoring active volcanoes rely on the installation of arrays of equipment, such as seismometers, gas detectors and tilt metres (e.g. Aiuppa et al., 2010). In addition to being expensive, these are also potentially hazardous to install (McGonigle et al., 2008). Given that over 750 million people live within the shadow of active or dormant volcanoes, many of which lie within developing nations that lack the resources to deploy expensive equipment, the development of a low-cost, UAV-based monitoring system has far-reaching implications. We envisage that such a system would work in a two-fold manner: looking at changes in the terrain from the DSM; and changes in the surface temperature from the thermal imagery. Both methods are standard practice in volcanic monitoring using either ground-based sensors and/or data from satellite altimetry (e.g. Gabrieli et al., 2016; Harris and Stevenson, 1997).

The workflow presented in this paper (Fig. 3) could be used to develop a system in which autonomous UAV flights over a set period of days, weeks or months are used to 
WAKEFORD et al. Combining thermal imaging with photogrammetry of an active volcano using UAV: an example from Stromboli, Italy

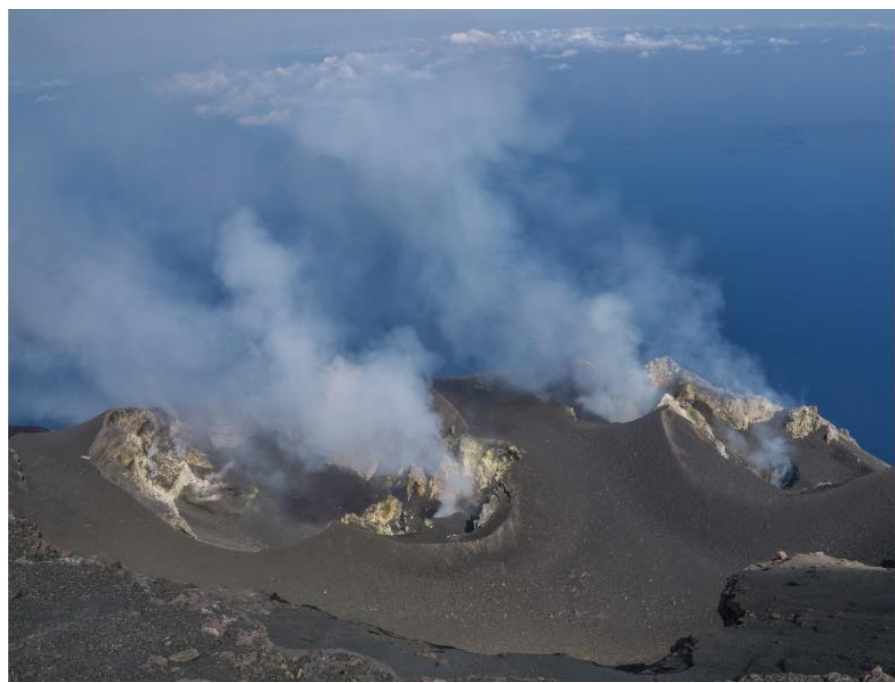

(a)

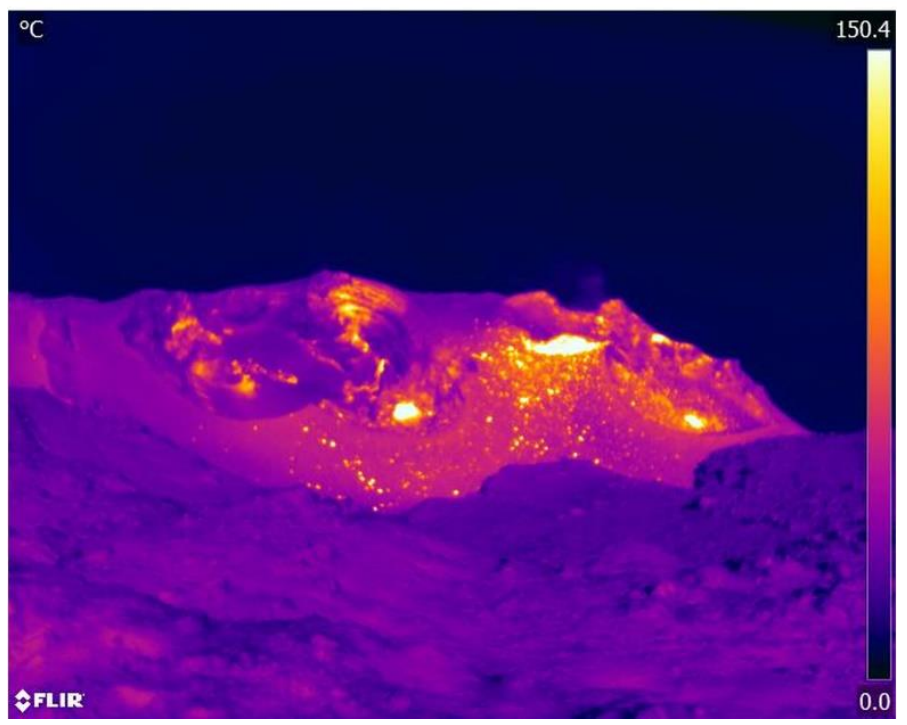

(b)

FIG 9. Comparison of (a) visual RGB images and (b) thermal infrared images, taken from similar positions, illustrating how thermal sensors can "see" through curtains of smoke at the crater zone and identify otherwise hidden vents. Photographs taken from the Vancori-Pizzo Sopra La Fossa balcony (Fig. 1), overlooking the three craters, facing northwest. Distance between C1 western edge and C3 northern edge (Fig. 1) is $53 \mathrm{~m}$.

generate time-lapse terrain and thermal models. Monitoring with the terrain models would involve simply comparing successive terrain surfaces. UAV-based photogrammetry is highly suited to volcanic monitoring because the upper reaches of active volcanoes are commonly covered with recent lava flows and are unvegetated. Successive thermal flights would need to be calibrated to remove the effects of air temperature and solar radiation at different times of the year. This could be achieved through the installation of a series of 
targets of known reflectivity, which are routinely scanned and used as a basis for corrections. The magnitude of changes in terrain that occur prior to an eruption are significantly greater than errors associated with the generation of UAV-based photogrammetric topography. They would be relatively easy to spot. Thermal activity, such as venting of gases from fissures and general heating of the ground prior to eruption, are also well within the magnitude of what can be mapped and detected by such a system.

A set flight path around a target volcano could be programmed into the UAV allowing automated data acquisition, removing the need for advanced piloting skills after the initial installation. This way, the UAV can trace the same flight path as many times as necessary, capturing imagery from the same perspectives on each survey, reducing survey uncertainty. Once captured, data could be processed by automated workflow and automatically compared to previous surveys, reducing manpower and time in generating warnings of potential eruptions. The workflow presented in this paper is the first stage towards developing a low-cost, autonomous system for monitoring volcanoes and predicting eruptions.

\section{Challenges of the Workflow}

As with any photogrammetric application, there are a few challenges that must be addressed when conducting any study. Firstly, when deploying a UAV in the field, its limitations and caveats must be considered. An appropriate flying altitude must be adopted as the flight safety and image resolution can be affected (Tarigan et al., 2017). Maximum flight altitudes are dependent on the model of the UAV deployed. Most UAVs used in volcano monitoring tend to be either mini or close-range UAVs, which have maximum flight altitudes of $300 \mathrm{~m}$ and 3,000 m, respectively (Dalamagkidis, 2015). The deployment of the UAV itself is limited based on its payload weight, battery power and the permissible distance between the UAV and the operator, as well as between the UAV and the hazardous target area (Blackett, 2017). Moreover, good weather conditions are favourable as drone deployment can be hindered by high winds and dense cloud cover (Westoby et al., 2012).

Secondly, the acquisition of TIR imagery has its challenges. The temperature measurements recorded by the thermal camera must be calibrated periodically, otherwise errors will be recorded in the results (Sheng et al., 2010). The emissivity of volcanic surfaces vary depending on the mineralogy and recorded electromagnetic waveband and, consequently, can influence acquired data (Blackett, 2017). Emissivity is the minimum reflectance of a surface and is unitless. Buongiorno et al. (2002) found that basaltic lavas have a typically high and stable emissivity of between 0.95 and 0.98 . Salisbury and D'Aria (1992) found emissivity values for various volcanic rock types, including andesite (0.69 $1.86)$, diorite (0.79), picrite $(0.93-1.45)$, rhyolite (1.90), and granite $(2.04-2.96)$, recorded in the $8-14 \mu \mathrm{m}$ waveband. Solar radiation absorbed by the ground surface can give a higher recorded temperature result by several tens of degrees (Calvari et al., 2005). Also, gas and aerosol absorption can affect TIR imagery (Calvari et al., 2005). Underestimates of $\sim 400 \mathrm{~K}$ can result when monitoring a volcanic source with an actual temperature of 1200 $\mathrm{K}$ (Sawyer and Burton, 2006).

Lastly, challenges can arise when processing the respective photogrammetry datasets. As previously described, RGB and TIR images must be geo-referenced and oriented, either in the pre- or post-processing data stage. To obtain a more accurate $3 \mathrm{D}$ photogrammetric model, images acquired with direct, overhead and orthogonal points of view must be 
WAKEFORD et al. Combining thermal imaging with photogrammetry of an active volcano using UAV: an example from Stromboli, Italy

selected (e.g. Calvari et al., 2005). Volcanic areas covered in dense vegetation or with a large crater lake are probably not well reconstructed using the UAV-MVS technique due to their homogeneous textures (Harwin and Lucieer, 2012).

\section{CONCLUSIONS}

There are no previously published 3D thermal models of an active volcano. We have presented the first example with our case study from Stromboli. This is part of a long-term project which aims to develop a UAV-based system that can be used for the low-cost monitoring of volcanoes. The case study presented outlines the workflow (Fig. 3) that has been developed to produce a 3D thermal photogrammetric model (Fig. 8). This demonstrates that TIR images can be successfully applied to perform photogrammetric processing and generating 3D spatial data which could be used in researching and monitoring volcanic activity. The combination of both RGB and TIR datasets significantly increases the amount of detail on reconstructed surfaces and provides an improved method for geometric accuracy. It is not required that the RGB and TIR imagery be taken from the same positions or even during one single UAV flight, proving more flexibility with research campaigns and ensuring the datasets can be acquired during optimum conditions. Having a 3D thermal model allows us to investigate the thermal differences across the whole study area at the same time, giving more information about the surface geometry and a wider perspective than that given by individual 2D images (Maset et al., 2017).

Ever-continuous enhancements in UAV technology and application can provide opportunities for them to aid relevant governments and decision-making bodies to assess the potential risk and damage to areas affected by impending geohazards efficiently and effectively (Tarigan et al., 2017).

When acquired in real-time, thermal infrared datasets can be an extremely valuable hazard assessment tool (Harris et al., 2003; Sheng et al., 2010). Our workflow demonstrates a powerful, relatively cheap and easy-to-use technique to monitor volcanic activity. It can be easily deployed to track thermal changes over time without exposing the operators to any geohazards. Further research can potentially produce a fully automated and robust system that can be used with a variety of sensors, including atmospheric sensors, portable seismometers or gas sensors. On-site geo-referencing of the captured imagery could be feasible with high-end navigation sensors, such as differential global position system (DGPS) or inertial navigation unit (INS), incorporated into the UAVs (Remondino et al., 2011). The process of 3D photogrammetry could also evolve in the future with the introduction of time-lapse (4D) photogrammetry. Previous studies have already exploited the advantages of time-lapse monitoring to 2D photogrammetry, e.g. for tracking snow cover (e.g. Parajka et al., 2012); monitoring frost creep dynamics (e.g. Matsuoka, 2014), and for monitoring landslide development (e.g. Gabrieli et al., 2016). The time-lapse approach to SfM photogrammetry would be more than feasible for use on 3D models, as it can utilise the different overlapping perspectives of the imagery that $2 \mathrm{D}$ monoscopic applications do not possess (Eltner et al., 2017).

\section{ACKNOWLEDGMENTS}

We would like to thank the INGV-CT for granting permission to conduct the UAV 
surveys over Stromboli volcano. This work was supported by the School for Early Career Researchers at the University of Aberdeen. Dougal Jerram is partly funded through a Norwegian Research Council Centres of Excellence project (project number 223272, CEED). The team would like to thank Angelo Cristaudo for logistical help during the fieldwork efforts on Stromboli.

\section{REFERENCES}

Aiuppa, A., Bertagnini, A., Métrich, N., Moretti, R., Di Muro, A., LiuZzo, M. and Tamburello, G., 2010. A model of degassing for Stromboli volcano. Earth and Planetary Science Letters, 295: 195-204.

BBC NEws, 2019. https://www.bbc.co.uk/news/world-europe-48857422 (Accessed 4th July 2019).

BELLIAN, J.A., KERANS, C. and JENNETTE, D.C., 2005. Digital outcrop models: Applications of terrestrial scanning lidar technology in stratigraphic modeling. Journal of Sedimentary Research, 75(2): 166-176.

BLACKETT, M., 2017. An overview of infrared remote sensing of volcanic activity. Journal of Imaging, 3(2): 1337.

Bonaccorso, A., Calvari, S., Garf, G., Lodato, L.K and Patanè, D., 2003. Dynamics of the December 2002 flank failure and tsunami at Stromboli volcano inferred by volcanological and geophysical observations. Geophysical Research Letters, 30(18): 1941-1945.

Brumana, R., Oreni, D., Van Hecke, L., Barazzetti, L., Previtali, M., Roncoroni, F. and Valente, R., 2013. Combined geometric and thermal analysis from UAV platforms for archaeological heritage documentation. ISPRS Annals of the Photogrammetry, Remote Sensing and Spatial Information Sciences, 2(5/W1): 49-54.

Buckley, S.J., Enge, H.D., CARLSSON, C. and Howell, J.A., 2010. Terrestrial laser scanning for use in virtual outcrop geology. The Photogrammetric Record, 25(131): 225-239.

Buckley, S.J., HowEll, J.A., ENGE, H.D. and KuRZ, T.H., 2008. Terrestrial laser scanning in geology: Data acquisition, processing and accuracy considerations. Journal of the Geological Society, 165(3): 625-638.

Buckley, S.J., KurZ, T.H., Howell, J.A. and SchneIDER, D., 2013. Terrestrial lidar and hyperspectral data fusion products for geological outcrop analysis. Computers and Geosciences, 54: 249-258.

Buckley, S.J., Ringdal, K., Naumann, N., Dolva, B., KurZ, T.H., Howell, J.A. and Dewez, T.J.B., 2019. LIME: Software for 3-D visualization, interpretation, and communication of virtual geoscience models. Geosphere, 15(1): 222-235.

Buongiorno, M.F., Realmuto, V.J. and Doumaz, F., 2002. Recovery of spectral emissivity from Thermal Infrared Multispectral Scanner imagery acquired over a mountainous terrain: A case study from Mount Etna Sicily. Remote Sensing of Environment, 79: 123-133.

Calvari, S., Spampinato, L., Lodato, L., Harris, A.J.L., Patrick, M.R., Dehn, J., Burton, M.R. and ANDRONICO, D., 2005. Chronology and complex volcanic processes during the 2002-2003 flank eruption at Stromboli volcano (Italy) reconstructed from direct observations and surveys with a handheld thermal camera. Journal of Geophysical Research: Solid Earth, 110(B02201): 1-23.

Capaldi, G., Guerra, I., Lo Bascio, A., Luongo, G., Pece, R., Rapolla, A., Scarpa, R., Del Pezzo, E., Martini, M., Ghiara, M.R., Lirer, L., Munno, R. and La VolPe, L., 1978. Stromboli and its 1975 eruption. Bulletin Volcanologique, 41(3): 259-285.

CHIO, S.-H. and LIN, C.-H., 2017. Preliminary study of UAS equipped with thermal camera for volcanic geothermal monitoring in Taiwan. Sensors, 17: 1649-1666.

Cottrell, E., 2015. Global distribution of active volcanoes. Chapter 1 in Volcanic Hazards, Risks, and Disasters (Eds. J.F. Shroder and P. Papale). Elsevier, Boston, USA. 505 pages: 1-16.

DALAMAGKIDIS, K., 2015. Classification of UAVs. Chapter 5 in Handbook of Unmanned Aerial Vehicles (Eds. K.P. Valavanis and G.J. Vachtsevanos). Springer Reference, Dordrecht, The Netherlands. 3022 pages: 8391.

De Fino, M., La Volpe, L., Falsaperla, S., Frazzetta, G., Neri, G., Francalanci, L., Rosi, M., Sbrana, A., 1988. The Stromboli eruption of December 6, 1985 - April 25, 1986: Volcanological, petrological and seismological data. Rendiconti della Societa Italiana di Mineralogia e Petrologia, 43: 1021-1038.

Donato Melita, C., Longo, D., Muscato, G. and Giudice, G., 2015. Measurement and exploration in volcanic environments. Chapter 111 in Handbook of Unmanned Aerial Vehicles (Eds. K.P. Valavanis and G.J. Vachtsevanos). Springer Reference, Dordrecht, The Netherlands. 3022 pages: 2668-2692.

Eltner, A., Kaiser, A., ABellan, A. and Schindewolf, M., 2017. Time lapse structure-from-motion photogrammetry for continuous geomorphic monitoring. Earth Surface Processes and Landforms, 42: 
WAKEFORD et al. Combining thermal imaging with photogrammetry of an active volcano using UAV: an example from Stromboli, Italy

$2240-2253$

Enge, H.D., BuCKLEY, S.J., Rotevatn, A. and Howell, J.A., 2007. From outcrop to reservoir simulation model: Workflow and procedures. Geosphere, 3(6): 469-490.

FLIR SYSTEMS INC., 2019. https://flir.custhelp.com/app/answers/detail/a_id/1729/ /radiometric-jpegimages/session/L2F2LzEvdGltZS8xNTY5MjQ4MzE0L2dlbi8xNTY5MjQ4MzE0L3NpZC9mVVpVWS U3RSU3RU9mc2F1YzBXTVN1Q3JkQTVOckhyb1F3JTdFWUNNT19HQ2hBeVJrS0Z4bkRIZ1ZIRzhY Q1p4RkNocTdDOHZVbEhPeTI5UIRIRk (Accessed 23rd September 2019).

Fonstad, M.A., Dietrich, J.T., Courville, B.C., Jensen, J.L. and Carbonneau, P.E., 2013. Topographic structure from motion: A new development in photogrammetric measurement. Earth Surface Processes and Landforms, 38: 421-430.

FurukawA, Y. and PONCE, J., 2010. Accurate, dense, and robust multiview stereopsis. IEEE Transactions on Pattern Analysis and Machine Intelligence, 32(8): 1362-1376.

GABrieli, F., CORAin, L. and VetTORE, L., 2016. A low-cost landslide displacement activity assessment from time-lapse photogrammetry and rainfall data: Application to the Tessina landslide site. Geomorphology, 269: 56-74.

Gade, R. and Moeslund, T.B., 2014. Thermal cameras and applications: A survey. Machine Vision and Applications, 25: 245-262.

Ganci, G., Vicari, A., Fortuna, L. and Del Negro, C., 2011. The HOTSAT volcano monitoring system based on combined use of SEVIRI and MODIS multispectral data. Annals of Geophysics, 54(5): 544-550.

HARris, A.J.L., JohnSON, J.B., Horton, K., GARbeIl, H., RAMM, H., PILGER, E., FlynN, L.P., Mouginis-MARK, P.J., Pirie, D., Donegan, S., Rothery, D.A., RIPEPE, M. and MARChetTI, E., 2003. Ground-based infrared monitoring provides new tool for remote tracking of volcanic activity. Eos, Transactions, American Geophysical Union, 84(40): 409-424.

HARRIS, A.J.L. and STEVENSON, D.S., 1997. Thermal observations of degassing open conduits and fumaroles at Stromboli and Vulcano using remotely sensed data. Journal of Volcanology and Geothermal Research, 76: 175-198.

Harvey, M., Harvey, C., Rowland, J. V. and Luketina, K.M., 2016. Drones in geothermal exploration: Thermal infrared imagery, aerial photos and digital elevation models. Proceedings of the $6^{\text {th }}$ African Rift Geothermal Conference: 1-12.

HARWIN, S. and LUCIEER, A., 2012. Assessing the accuracy of georeferenced point clouds produced via multiview stereopsis from Unmanned Aerial Vehicle (UAV) imagery. Remote Sensing, 4: 1573-1599.

HodGETTS, D., 2013. Laser scanning and digital outcrop geology in the petroleum industry: A review. Marine and Petroleum Geology, 46: 335-354.

Hoegner, L., TutTas, S., Xu, Y., Eder, K. and Stilla, U., 2016. Evaluation of methods for coregistration and fusion of RPAS-based 3D point clouds and thermal infrared images. International Archives of the Photogrammetry, Remote Sensing and Spatial Informaiton Sciences, 41(B3): 241-246.

Howell, J.A., Martinius, A.W. and GooD, T.R., 2014. The application of outcrop analogues in geological modelling: A review, present status and future outlook. Chapter in Sediment-Body Geometry and Heterogeneity: Analogue Studies for Modelling the Subsurface (Eds. A.W. Martinius, J.A. Howell and T.R. Good). Geological Society, London, Special Publications, 387. 293 pages: 1-25.

INGV, 2019. www.ct.ingv.it/en/real-time-seismic-signal.html (Accessed $4^{\text {th }}$ July 2019).

JAMES, M.R. and RoBSON, S., 2014. Mitigating systematic error in topographic models derived from UAV and ground-based image networks. Earth Surface Processes and Landforms, 39: 1413-1420.

JAMES, M.R. and RoBSON, S., 2012. Straightforward reconstruction of 3D surfaces and topography with a camera: Accuracy and geoscience application. Journal of Geophysical Research: Solid Earth, 117(F03017): 1-17.

Jerram, D.A., SCARTh, A. and TANGUY, J.-C. (Eds.), 2017. Volcanoes of Europe, second edition. Dunedin Academic Press. 288 pages: $27-45$.

JORDAN, B.R., 2015. A bird's-eye view of geology: The use of micro drones/UAVs in geologic fieldwork and education. GSA Today, 25(7): 50-52.

KuRZ, T.H., Buckley, S.J., Howell, J.A. and SchneIDER, D.J., 2008. Geological outcrop modelling and interpretation using ground based hyperspectral and laser scanning data fusion. International Archives of the Photogrammetry, Remote Sensing and Spatial Information Sciences, 37: 1-6.

Lodato, L., Spampinato, L., Harris, A.J.L., Calvari, S., Dehn, J. and PATrick, M.R., 2007. The morphology and evolution of the Stromboli 2002-2003 lava flow field: An example of a basaltic flow field emplaced on a steep slope. Bulletin of Volcanology, 69: 661-679.

LOMBARDO, V., 2016. Influence of pre-existing topography on downflow lava discharge rates estimated from thermal infrared airborne data. Geophysical Journal International, 205: 122-133.

LOPES, R.M.C. (Ed.), 2005. The Volcano Adventure Guide. Cambridge University Press, Cambridge, United 
Kingdom. 352 pages: $177-195$.

MAdONIA, P. and FIORDILINO, E., 2013. Time variability of low-temperature fumaroles at Stromboli island (Italy) and its application to volcano monitoring. Bulletin of Volcanology, 75: 776-788.

Maset, E., Fusiello, A., Crosilla, F., Toldo, R. and ZorZetTo, D., 2017. Photogrammetric 3D building reconstruction from thermal images. ISPRS Annals of the Photogrammetry, Remote Sensing and Spatial Information Sciences, 4(2/W3): 25-32.

MAtsuOKA, N., 2014. Combining time-lapse photography and multisensor monitoring to understand frost creep dynamics in the Japanese Alps. Permafrost and Periglacial Processes, 25: 94-106.

MCGiMSEY, R.G., SCHNEIDER, D.J., NEAL, C.A. and ROACH, A.L., 1999. Use of FLIR observations during eruption response at two Alaskan volcanoes. Eos, Transactions, American Geophysical Union, 80(46).

McGonigle, A.J.S., Aiuppa, A., Giudice, G., Tamburello, G., Hodson, A.J. and Gurrieri, S., 2008. Unmanned aerial vehicle measurements of volcanic carbon dioxide fluxes. Geophysical Research Letters, 35(L06303); 1-4.

Morgan, D.J., Jerram, D.A., Chertkoff, D.G., Davidson, J.P., Pearson, D.G., Kronz, A. and Nowell, G.M., 2007. Combining CSD and isotopic microanalysis: Magma supply and mixing processes at Stromboli Volcano, Aeolian Islands, Italy. Earth and Planetary Science Letters, 260(3-4): 419-431.

NIEMINSKI, N.M. and GRAHAM, S.A., 2017. Modeling stratigraphic architecture using small unmanned aerial vehicles and photogrammetry: Examples from the Miocene East Coast Basin, New Zealand. Journal of Sedimentary Research, 87(2): 126-132.

Nishar, A., Richards, S., Breen, D., Robertson, J. and Breen, B., 2016. Thermal infrared imaging of geothermal environments and by an unmanned aerial vehicle (UAV): A case study of the Wairakei Tauhara geothermal field, Taupo, New Zealand. Renewable Energy, 86: 1256-1264.

OPPENHEIMER, C. and YiRgu, G., 2002. Thermal imaging of an active lava lake: Erta 'Ale volcano, Ethiopia. International Journal of Remote Sensing, 23(22): 4777-4782.

PARAJKA, J., HAAS, P., KIRNBAUER, R., JANSA, J. and BlÖSChL, G., 2012. Potential of time-lapse photography of snow for hydrological purposes at the small catchment scale. Hydrological Processes, 26: 3327-3337.

Patanè, D., Barberi, G., De Gori, P., Cocina, O., Zuccarello, L., García-Yeguas, A., Castellano, M., D'Alessandro, A. and SGroI, T., 2017. The shallow magma chamber of Stromboli Volcano (Italy). Geophysical Research Letters, 44: 6589-6596.

PIOLI, L., PISTOLESI, M. and Rosi, M., 2014. Transient explosions at open-vent volcanoes: The case of Stromboli (Italy). Geology, 42(10): 863-866.

Pisciotta, A., CAPASSO, G. and MADONIA, P., 2016. Aerial monitoring in active mud volcano by UAV technique. EGU General Assembly, 18.

Pringle, J.K., Howell, J.A., Hodgetts, D., Westerman, A.R. and Hodgson, D.M., 2006. Virtual outcrop models of petroleum reservoir analogues: A review of the current state-of-the-art. First Break, 24(3): 3342.

Remondino, F., BarazZetti, L., NeX, F., Scaioni, M. and SarazZi, D., 2011. UAV photogrammetry for mapping and 3D modeling: Current status and future perspectives. International Archives of the Photogrammetry, Remote Sensing and Spatial Information Sciences, 38-1(C22): 25-31.

Ripepe, M., Marchetti, E., Poggi, P., Harris, A.J.L., Fiaschi, A. and Ulivieri, G., 2004. Seismic, acoustic, and thermal network monitors the 2003 eruption of Stromboli Volcano.Eos, Transactions, American Geophysical Union, 85(35): 329-336.

Romeo, G., Di Stefano, G., MaZzini, A., Iarocci, A. and Caramelli, A., 2016. Photogrammetry surveys and mosaic: A useful tool to monitor active zones. Applications to the Indonesian Lusi eruption site. $E G U$ General Assembly, 18.

SALISBURY, J.W. and D'ARIA, D.M., 1992. Emissivity of terrestrial materials in the 8-14 $\mu \mathrm{m}$ atmospheric window. Remote Sensing of Environment, 42: 83-106.

SAWYER, G.M. and BuRTON, M.R., 2006. Effects of a volcanic plume on thermal imaging data. Geophysical Research Letters, 33(L14311): 1-4.

Sheng, H., Chao, H., Coopmans, C., Han, J., McKeE, M. and Chen, Y., 2010. Low-cost UAV-based thermal infrared remote sensing: Platform, calibration and applications. Proceedings of 2010 IEEE/ASME International Conference on Mechatronic and Embedded Systems and Applications, MESA 2010: 38-43.

Skarlatos, D., Procopiou, E., Stavrou, G. and Gregoriou, M., 2013. Accuracy assessment of minimum control points for UAV photography and georeferencing. Proceedings of the First International Conference on Remote Sensing and Geoinformation of the Environment (RSCy2013), 8795: 879514.

SLedZ, A., Unger, J. and HeIPKE, C., 2018. Thermal IR imaging: Image quality and orthophoto generation. International Archives of the Photogrammetry, Remote Sensing and Spatial Information Sciences, 42(1): 413-420. 
WAKEFORD et al. Combining thermal imaging with photogrammetry of an active volcano using UAV: an example from Stromboli, Italy

Spampinato, L., Calvari, S., OpPenheimer, C. and Boschi, E., 2011. Volcano surveillance using infrared cameras. Earth Science Reviews, 106: 63-91.

TARIgAN, A.P.M., SUWARDHI, D., FAJRI, M.N. and FAHMI, F., 2017. Mapping a volcano hazard area of Mount Sinabung using drone: Preliminary results. IOP Conference Series: Materials Science and Engineering, 180(012277): $1-9$

TIBALDI, A., 2003. Influence of cone morphology on dykes, Stromboli, Italy. Journal of Volcanology and Geothermal Research, 126: 79-95.

TiBALDI, A., 2001. Multiple sector collapses at Stromboli volcano, Italy: How they work. Bulletin of Volcanology, 63: $112-125$.

TONKIN, T.N. and MidGLEY, N.G., 2016. Ground-control networks for image based surface reconstruction: An investigation of optimum survey designs using UAV derived imagery and structure-from-motion photogrammetry. Remote Sensing, 8: 786-794.

Westoby, M.J., BRASington, J., GlasSER, N.F., HAMBrey, M.J. and ReynOldS, J.M., 2012. "Structure-fromMotion" photogrammetry: A low-cost, effective tool for geoscience applications. Geomorphology, 179: 300-314.

WiLkinson, A., 2017. Game of drones. Geoscientist: The Fellowship Magazine of the Geological Society of London, 27(2): 10-15.

Résumé

Zusammenfassung

Resumen 